University of Windsor

Scholarship at UWindsor

\title{
Motivational and Personality Predictors of Body Esteem in High- and Low-Frequency Exercisers
}

B. L. Segatto

Kathryn Lafreniere

University of Windsor

Follow this and additional works at: https://scholar.uwindsor.ca/psychologypub

Part of the Psychology Commons

\section{Recommended Citation}

Segatto, B. L. and Lafreniere, Kathryn. (2013). Motivational and Personality Predictors of Body Esteem in High- and Low-Frequency Exercisers. Journal of Motivation, Emotion, and Personality, 1, 27-35.

https://scholar.uwindsor.ca/psychologypub/4

This Article is brought to you for free and open access by the Department of Psychology at Scholarship at UWindsor. It has been accepted for inclusion in Psychology Publications by an authorized administrator of Scholarship at UWindsor. For more information, please contact scholarship@uwindsor.ca. 


\title{
Motivational and Personality Predictors of Body Esteem in High- and Low-Frequency Exercisers
}

\author{
Bianca L. Segatto and Kathryn D. Lafreniere \\ Psychology Department, University of Windsor, Windsor, Ontario, Canada
}

\begin{abstract}
Active living is imperative to maintaining good health, and becoming involved in regular exercise at a young age is fundamental. The purpose of this study was to examine motivation for exercise among university students in relation to metamotivational dominance and body esteem. Participants in this study were 106 undergraduate students who were recruited from their psychology departmental participant pool and from the campus exercise facility at a mediumsized Canadian university. Participants completed an inventory that included the Motivational Style Profile, Big Five Inventory-10, Behavioral Regulation in Exercise Questionnaire, and the Body Weight and Image Self-Esteem Evaluation Questionnaire to assess personality, exercise motivation, and body esteem. High-frequency exercisers were found to be more paratelic dominant than low-frequency exercisers, and scored significantly higher on intrinsic, identified, and introjected regulation, indicating that they exercised for enjoyment, valued exercise outcomes, and wanted to avoid negative emotions associated with not exercising. Among highfrequency exercisers, positive body esteem was associated with high intrinsic and low extrinsic motivation for exercise, paratelic dominance, negativism dominance, and low neuroticism. For low-frequency exercisers, significant correlates of positive body esteem were autic mastery dominance, low BMI, low neuroticism, and lower levels of extrinsic and introjected motivation. Findings are discussed in terms of healthy and unhealthy motivations for exercise, and recommendations are made for tailoring health promotion strategies to metamotivational dominance.
\end{abstract}

Keywords: motivation, exercise, body esteem, telic dominance

Exercise has proven to be effective in maintaining general health and well being, managing disease and improving longevity (Barnes, 2010). For the purpose of this investigation, exercise is defined as planned, structured and repetitive physical activity designed to improve or maintain fitness (U.S. Department of Health and Human Services, 2000). It might be assumed that the known benefits of physical activity would be sufficient motivation for people to adopt a regular exercise regimen. Nonetheless, obesity and inactivity have increased dramatically over the past few decades in North America. In 2007 - 2009, the obesity rate for adults in Canada was $24.1 \%$, while the prevalence of obesity in the United States was even higher, at $34.4 \%$. These rates represent a significant increase since 1986, with prevalence of obesity rising by 10 percentage points in Canada and by 12 percentage points in the United States during this period. Among women, those aged 20 to 39 experienced the greatest

Correspondence concerning this article should be addressed to Bianca L. Segatto, 4713 Kominar Crt, Windsor, ON, N9G 2W6, Canada. E-mail: bianca.segatto@mail.mcgill.ca increase in obesity during this period (Shields, Carroll, \& Ogden, 2011).

While the health benefits of exercise are now well established (e.g., Barnes, 2010), a key factor in health promotion is to understand what motivates individuals to engage in exercise as well as adhere to it. Expanding the breadth of knowledge in this area will aid in the development of programs and interventions that would be more effective in increasing exercise participation and adherence. Individualized programs can target specific skills or abilities, and take into account individual differences in personality and motivation to create a program suited to the person's unique needs and interests. The present study was undertaken to examine specific predictors of exercise motivation in university students, in order to inform strategies for increasing exercise participation.

Participation in physical activity is most often associated with leisure time, since the majority of occupations today are not high in physical demands (U.S. Department of Health and Human Services, 2000). Given that many exercise programs focus on attending a fitness center, they often neglect sport participation. Sports and recreation can be just as effective as an exercise program at a fitness center, depending on the individual's level of involvement. However, preferred style of physical activity may be contingent upon the 
individual and his or her personality and motivational tendencies. This is yet another reason to explore motivational styles for exercise. Previous research (Kilpatrick, Hebert, \& Bartholomew, 2005) has shown that students were more intrinsically motivated toward sport participation, but more extrinsically motivated toward exercise. Kilpatrick et al. (2005) also found that increased maintenance and adherence to exercise behaviors were associated with intrinsic motivation. These findings suggest that there is a need to understand individuals' various motivations for exercise, and that focusing on areas in which people are intrinsically motivated may maximize the effectiveness of an exercise program.

One context in which extrinsic motivation for exercise is likely to operate relates to body image concerns. In North American culture, there is an over-emphasis on social attractiveness and slender bodies, especially for women. A number of articles have discussed women's "normative discontent" with their bodies (e.g., Rodin, Silberstein, \& Striegel-Moore, 1984; Tantleff-Duff, Barnes, \& Larose, 2011), or the idea that women strive to be thinner regardless of their body mass index (BMI). Fewer studies have focused their attention on male body image satisfaction, but a number of investigations have shown body image concerns among males, as well, with an emphasis on losing body fat and increasing muscle tone (e.g., Olivardia, Pope, Borowiecki, \& Cohane, 2004). The present study examined motivation for exercise among university students in relation to personality, metamotivational dominance, and body esteem.

\section{Relevant Theoretical Frameworks}

Self-determination theory (Deci \& Ryan, 1985, 2000) posits that personality development and behavioral regulation are based on psychological needs for competence, relatedness, and autonomy. One facet of self-determination theory examines conditions that influence intrinsic and extrinsic motivation (Ryan \& Deci, 2000) and these concepts have been applied to understanding exercise behavior. Intrinsic motivation is the desire to engage in an activity because it is enjoyable and inherently satisfying for the individual. Extrinsic motivation is the motivation to engage in an activity for some kind of external outcome. The theory suggests that within extrinsic motivation, there is a continuum that ranges from more controlled behavioral regulations to those that are more autonomous. External regulation refers to activities in which an individual is required or pressured to do something based on external demands or rewards (e.g., engaging in exercise because your doctor says that you should do so). Introjected regulation is also somewhat controlled, and serves to protect the ego. It involves trying to avoid feelings such as guilt or anxiety (e.g., exercising because one is ashamed to be sedentary). Identified regulation is somewhat more autonomous, and refers to behavior that is conscious and has great value to the individual (e.g., exercising because one val- ues the benefits of physical activity). Intrinsic regulation is autonomous, and refers to engaging in behavior because it is inherently pleasurable (i.e., exercising for fun). The present study examines these categories of behavioral regulation in relation to motivation for exercise behavior and body esteem.

While self-determination theory broadly describes the continuum of behavioral regulation for exercise, it may be limited in explaining why individuals occupy a particular position along the continuum of behavioral regulation. That is, why do some people express more autonomous regulation for exercise, while others are more influenced by more controlled regulation? A theory that examines both inter- and intra-individual differences in our experience of motivation is needed to more precisely explain individual differences in motivation for exercise. Reversal theory is concerned primarily with how we experience motivation and how this influences our behavior and personality functioning, and suggests that our actions at any given time are guided by opposing metatmotivational modes (Apter, 2005, 2007). According to the theory, we regularly switch between these opposing states, but may be dominant in one particular state over its opposite. The main pairs advanced by reversal theory are the telic and paratelic modes (i.e., goal-oriented vs. activity-oriented), negativistic and conformist modes, mastery and sympathy modes, and the autic (self-oriented) and alloic (other-oriented) modes. The autic and alloic modes are often considered in relation to the mastery and sympathy modes, to allow for examination of situations in which one is trying to control his or her own behavior (autic mastery) vs. experiencing power by identifying with a group or team (alloic mastery).

The present study will examine all of these mode-pairs, but of particular interest are the telic and paratelic modes. The telic state is serious and goal-oriented, in which activities are seen to be a means to an end. Conversely, the paratelic state is playful and activity-oriented, in which activities are intended to provide immediate enjoyment (Apter, 2005). Therefore, it might be speculated that people who are telic dominant might be more extrinsically motivated to engage in exercise (i.e., based on exercise goals and value for the benefits of exercise), while those who are paratelic dominant might be more intrinsically motivated by the enjoyment of the activity itself.

A number of studies have examined motivation for physical activity in relation to reversal theory's metamotivational constructs. For example, Lindner and Kerr (2000) examined metamotivational orientation in sports participants (i.e., those taking part in physical activity at least once or twice per month) and non-participants. They found that telic motives, such as fitness, and paratelic motives, such as participating for fun, were the principal reasons for sports participation. While other factors from the remaining metamotivational pairs were also found to contribute to motiva- 
tion for sports, fitness and enjoyment had the greatest impact. In studies of large samples of schoolchildren and firstyear university students in Hong Kong, Lindner and Kerr (2000) found weak but consistent links between metamotivational dominance and motives for sport participation, with the strongest links between telic dominance and engaging in sports for serious-minded reasons.

Metamotivational dominance has also been examined in relation to eating disordered behavior and exercise dependence, both of which may be related to body esteem. Blaydon, Lindner, and Kerr (2002) examined metamotivational dominance in triathletes who were classified as having primary exercise dependence (engaging in excessive exercise, but without an eating disorder), secondary exercise dependence (exercise dependence that co-occurs with eating disordered behavior), and eating disordered (with no exercise dependence). Their findings indicated that, in general, triathletes tended to be dominant in the telic, conformist, autic, and mastery metamotivational modes. Individuals who were characterized by secondary exercise dependence (i.e., comorbid with eating disordered behavior) were significantly higher in telic dominance than the primary exercise dependence group. In addition, mastery dominance was higher in the groups that were characterized by eating disordered behavior than in the non-eating disordered groups.

\section{The Present Study}

The present study sought to examine reversal theory's metamotivational modes in conjunction with exercise motives based on self-determination theory, to develop a fuller picture of student exercise motivation and its consequences. Specifically, the following research questions were explored: 1) Do students who exercise regularly differ from lowfrequency exercisers in metamotivational dominance and exercise motivation? 2) Which personality variables, exercise motives, and metamotivational modes significantly predict body esteem in low-frequency and high-frequency exercisers? A secondary aim of the present investigation was to explore connections between motivational constructs derived from self-determination theory and metamotivational dominance.

\section{Method}

\section{Participants}

A total of 106 undergraduate student participants ranging from age 17 to $27(M=21.01, S D=2.16)$ were recruited from the University of Windsor. The sample was comprised of 75 females $(70.8 \%)$ and 31 males $(29.2 \%)$. Detailed demographic characteristics of the sample are shown in Table 1. Fifty-five participants were recruited through the Psychology Department participant pool and 51 were recruited from the student fitness center. Students received one bonus point toward their grade in any applicable psychology course in exchange for their participation. The study was cleared by the University of Windsor Psychology Research Ethics Board and all participants were treated in accordance with the ethical principles of the Canadian Psychological Association and the American Psychological Association.

\section{Measures}

Body Weight and Image Self Esteem (B-WISE). The B-WISE (Awad \& Voruganti, 2004) is a 12-item self-report measure in which participants respond on a 3-point Likert scale ("never", "sometimes", and "all the time") that assesses body weight and its psychosocial consequences. Negatively worded items were re-coded so that a high score reflects higher body esteem. The B-WISE was originally developed to assess the impact of weight fluctuation caused by psychotropic drug use, but its items are sufficiently general as to allow for its use in non-clinical populations. The B-WISE showed satisfactory internal consistency and test-retest reliability in validation samples, as well as strong discriminant validity between groups based on BMI scores (Awad \& Voruganti, 2004). The B-WISE was used as a brief, unidimensional measure of body esteem, and was found to show good internal consistency (Cronbach's alpha $=.80$ ) in the present investigation.

Behavioral Regulation in Exercise Questionnaire (BREQ). The Behavioral Regulation in Exercise Questionnaire was developed by Mullan, Markland and Ingledew (1997). It contains four subscales that measure external, introjected, identified, and intrinsic regulation of exercise behavior. The original questionnaire included 15 self-report items. It was modified for the present study to include an extra four items targeting additional extrinsic motivations (i.e., exercising to become more attractive, to increase muscle mass, for health reasons, and to lose weight). Participants responded to the items on a 4-point Likert scale ranging from 0 (not true for me) to 4 (very true for me). Previous studies have supported the multidimensional structure of the BREQ and have provided evidence of its reliability and validity across gender and individual exercisers versus non-exercisers (Wilson \& Rodgers, 2004), and the measure has also been used successfully with college student participants in previous research (e.g., Sidman, Fiala, \& D'Abundo, 2011). Internal consistency (Cronbach's alpha) of the BREQ subscales was found to be strong in the present study: extrinsic $=.89$, introjected $=.81$, identified $=.85$, and intrinsic $=$ .94.

Motivational Style Profile (MSP). The Motivational Style Profile (Apter, Mallows, \& Williams, 1998) is composed of 70 items in which responses are completed on a 6-point Likert scale, ranging from 1 (never) to 6 (always). The MSP contains subscales that allow for the 
Table 1

\begin{tabular}{|c|c|c|c|c|c|}
\hline Characteristic & $n$ & $\%$ & $M$ & $S D$ & Range \\
\hline \multicolumn{6}{|l|}{ Gender } \\
\hline Males & 31 & 29.2 & & & \\
\hline Females & 75 & 70.8 & & & \\
\hline Age & 106 & & 21.01 & 2.16 & $17.0-27.0$ \\
\hline \multicolumn{6}{|l|}{ Ethnicity } \\
\hline White/ European/ Canadian & 87 & 82.1 & & & \\
\hline Black/ African / Caribbean & 9 & 8.5 & & & \\
\hline East Asian & 5 & 4.7 & & & \\
\hline Middle Eastern & 4 & 3.8 & & & \\
\hline Aboriginal/ Metis/ First Nations & 1 & 0.9 & & & \\
\hline \multicolumn{6}{|l|}{ Year in University } \\
\hline $1 \mathrm{st}$ & 21 & 19.8 & & & \\
\hline 2nd & 25 & 23.6 & & & \\
\hline $3 \mathrm{rd}$ & 23 & 21.7 & & & \\
\hline 4th or higher & 37 & 34.9 & & & \\
\hline \multicolumn{6}{|l|}{ Academic Major } \\
\hline Psychology & 35 & 33.0 & & & \\
\hline Other Arts \& Social Sciences & 25 & 23.6 & & & \\
\hline Science & 14 & 13.2 & & & \\
\hline Business & 9 & 8.5 & & & \\
\hline Human Kinetics & 8 & 7.5 & & & \\
\hline Nursing & 7 & 6.6 & & & \\
\hline Engineering & 5 & 4.7 & & & \\
\hline Undeclared & 3 & 2.8 & & & \\
\hline Body Mass Index (BMI) & 105 & & 23.51 & 4.01 & $17.1-36.7$ \\
\hline
\end{tabular}

measurement of dominance in the major metamotivational modes posited by reversal theory (telic/paratelic, negativistic/conformist, mastery/sympathy, and autic/alloic). In addition, the autic/alloic modes can be considered in combination with the mastery/sympathy modes, to allow for the examination of autic-sympathy and autic-mastery modes (Apter \& Desselles, 2001). A dominance score is derived for each of these pairs of modes by subtracting the score for the second mode within a pair from the first (e.g., telic dominance is derived from the telic score minus the paratelic score). Previous studies have shown adequate internal consistency of most MSP subscales, and the measure's construct validity has been supported in many previous investigations (e.g., Lafreniere \& Cramer, 2006). In the present investigation, Cronbach's alpha coefficients were found to be adequate, ranging from .66 for the autic mastery and alloic sympathy subscales to .88 for alloic mastery.

Big Five Inventory-10 (BFI-10). The BFI-10 (Rammstedt \& John, 2007) is an abbreviated version of the Big Five Inventory (John, Donahue, \& Kentle, 1991). It contains 10 items that measure the Big Five factors of personality: neuroticism, extraversion, openness, agreeableness, and conscientiousness. Participants respond to items that conclude the statement "I see myself as someone who..." on a 5-point Likert scale ranging from 1 (disagree strongly) to 5 (agree strongly). The BFI-10 showed strong convergent validity, based on correlations with full-length Big Five measures, and excellent discriminant validity in standardization samples, and was chosen as a brief measure of Big Five personality factors in the present investigation based on its convergence with lengthier measures of the same personality constructs.

Background Questionnaire. The background questionnaire was comprised of questions to discern basic demographic data. It included questions regarding the participant's age, gender, cultural or ethnic background, student status, major, year in program, and employment status. Height and weight were also included in order to calculate BMI, as well as an assessment of level of exercise participation. There was also an open ended question asking about preferred style of exercise.

\section{Procedure}

Participants registered with the psychology participant pool were able to view available sessions and sign up for the study once it was posted online. These participants com- 
Table 2

\begin{tabular}{lccccc} 
Characteristics of Low and High Frequency & Exercisers $(N=106)$ \\
\cline { 1 - 5 } & \multicolumn{4}{c}{$\begin{array}{c}\text { Low Frequency } \\
\text { Exercisers }\end{array}$} & \multicolumn{2}{c}{ High Frequency } \\
Exercisers & \\
\cline { 2 - 5 } Measure & $M$ & $S D$ & $M$ & $S D$ & $t$ \\
\hline B-WISE & 21.51 & 3.02 & 21.82 & 2.90 & -0.55 \\
BREQ & & & & & \\
Extrinsic & 2.80 & 3.20 & 2.43 & 3.40 & 0.58 \\
Introjected & 3.93 & 3.54 & 5.65 & 2.70 & $-2.80^{* *}$ \\
Identified & 8.53 & 3.54 & 13.43 & 2.24 & $-8.44^{* * *}$ \\
Intrinsic & 8.53 & 4.16 & 12.89 & 3.14 & $-6.05^{* * *}$ \\
Telic Dominance & 4.04 & 4.95 & 1.51 & 6.29 & $2.31^{*}$ \\
Negativism Dominance & -6.89 & 6.28 & -5.35 & 6.82 & -1.21 \\
Autic Mastery Dominance & -0.76 & 4.91 & -0.08 & 4.10 & -0.78 \\
Alloic Mastery Dominance & -1.91 & 2.72 & -1.67 & 2.71 & -0.46 \\
Neuroticism & 6.02 & 1.95 & 5.47 & 2.05 & 1.41 \\
Extraversion & 6.51 & 1.61 & 6.98 & 1.89 & -1.38 \\
Openness & 6.91 & 1.83 & 7.12 & 1.56 & -0.63 \\
Agreeableness & 7.38 & 1.57 & 7.39 & 1.64 & -0.03 \\
Conscientiousness & 7.36 & 1.57 & 7.25 & 1.44 & 0.37 \\
\hline
\end{tabular}

Note. B-WISE = Body Weight and Image Self Esteem Questionnaire, BREQ

$=$ Behavioural Regulation in Exercise Questionnaire

$* p<.05 * * p<.01 * * * p<.001$

pleted the study in small groups of 4 to 8 participants in research rooms in the psychology department. Participants recruited through the student fitness center were provided with a small area in the lobby of the fitness center in which they could complete their questionnaire. All participants were given a brief overview of the study and then completed an informed consent form prior to filling out the questionnaire. Participants then received a packet containing the BFI-10, the B-WISE, MSP, BREQ and demographic questions. The entire process took participants approximately 30 minutes to complete, on average.

\section{Data Analysis}

Based on reported level of exercise, participants were classified into two groups: low-frequency exercisers (operationally defined as two or fewer times per week) and highfrequency exercisers (three or more times per week). This classification is consistent with groupings used in some previous research that have shown meaningful differences between low- and high-frequency exercisers on a number of motivational and exercise behaviors (e.g., Gammage, Hall, \& Martin Ginis, 2004; Rodgers \& Gauvin, 1998). High- and low-frequency exercisers were then compared on all measures through a series of $t$-tests and separate correlational analyses. Correlations among all scale measures were examined. Of particular interest were the correlations between body esteem and measures of motivation for exercise, meta- motivational dominance, and personality, as well as other correlations involving metamotivational dominance. Based on the correlations, predictors of body esteem were identified and multiple regression analyses were run with body esteem as the outcome variable.

\section{Results}

Internal consistency reliability (Cronbach's alpha) was calculated for all scales and subscales, as reported in the measures section, above. Since the BFI-10 subscales were comprised of only two items per subscale, their internal consistency reliability was not assessed. All other scales and subscales yielded adequate internal consistency reliability, with Cronbach's alpha coefficients ranging from .66 (for autic mastery and alloic sympathy) to .94 for intrinsic motivation on the BREQ.

Descriptive statistics on exercise frequency revealed that $52 \%$ of participants were considered low-frequency exercisers and $48 \%$ were classified as high-frequency exercisers. High-frequency exercisers were more likely to be in their upper years of university (i.e., 3rd or 4th year of university) than low-frequency exercisers, $t(104)=-2.95, p<.01$. Table 2 shows a comparison of low-frequency exercisers and high-frequency exercisers on body esteem, BREQ motivation subscales, and metamotivational dominance and personality measures. There were no significant differences between low- and high- frequency exercisers on BMI or on 
B-WISE body esteem. High-frequency exercisers reported higher levels of identified motivation $t(104)=-8.44, p<$ .001 , introjected motivation $t(104)=-2.80, p<.01$, and intrinsic motivation $t(104)=-6.05, p<.001$. High-frequency exercisers tended to be higher in paratelic dominance than low-frequency exercisers, $t(104)=2.31, p<.05$. No significant differences by high and low exercise groups were observed for the other metatmotivational modes, or for the Big Five personality dimensions.

Due to the differences between low- and high-frequency exercisers, correlational analyses and regression analyses to predict body esteem were run separately for low and high frequency exercisers. Significant negative correlates of body esteem among low- frequency exercisers were BMI $(r=$ $-.53, p<.001)$, neuroticism $(r=-.49, p<.01)$, extrinsic motivation $(r=-.40, p<.01)$, and introjected motivation $(r=-.34, p<.05)$, while autic mastery dominance was positively correlated with body esteem $(r=.33, p<.05)$. Among high-frequency exercisers, significant negative correlates of body esteem were neuroticism $(r=-.37, p<.01)$, extrinsic motivation $(r=-.41, p<.01)$, and telic dominance $(r=-.35, p<.05)$, while intrinsic motivation $(r=.42, p<$ $.01)$ and negativism dominance $(r=.30, p<.05)$ were positively associated with body esteem.

To address which variables were significant predictors of body esteem, regression analyses with body esteem as the criterion variable were conducted separately for the low and high exercise groups. The significant correlates of body esteem identified in the correlational analyses described above were entered as predictor variables into standard regression analyses. The final regression models are presented in Table 3. The regression analysis for low-frequency exercisers was significant, $R^{2}=.50, F(5,48)=9.52, p<.001$. Examination of the squared semi-partial correlation coefficients $\left(s r^{2}\right)$ indicates that for low- frequency exercisers, higher BMI $\left(s r^{2}=.16\right)$ and neuroticism $\left(s r^{2}=.06\right)$ were significant predictors of low body esteem, accounting for $16 \%$ and $6 \%$ of the variance in body esteem, respectively. The regression model for high-frequency exercisers was also significant, $R^{2}=.36, F(5,45)=5.03, p<.01$. For the highfrequency exercise group, neuroticism $\left(s r^{2}=.06\right)$ and extrinsic motivation $\left(s r^{2}=.06\right)$ were predictive of lower body esteem, with each of these significant predictors accounting for $6 \%$ of the variance in this outcome variable.

Additional correlational analyses were run on the full sample $(N=106)$ to examine associations between metamotivational dominance and the measures of exercise motivation and Big Five personality constructs. Telic dominance was found to be positively associated with conscientiousness $(r=.30, p<.01)$ and negatively related to extraversion $(r=$ $-.45, p<.001)$, identified motivation $(r=-.34, p<.001)$, and intrinsic motivation for exercise $(r=-.43, p<.001)$. Negativism dominance was positively correlated with ex-
Table 3

Final Regression Models Predicting Body Esteem

\begin{tabular}{lcccc}
\hline Predictor & $\beta$ & $t$ & $s r^{2}$ & $R^{2}$ \\
\hline \multicolumn{5}{c}{ Low-Frequency } \\
BMI Exercisers $(\mathrm{n}=54)$ \\
Neuroticism & -.42 & $-3.95^{* * *}$ & .16 & $.50^{* * * *}$ \\
Extrinsic Motivation & -.28 & $-2.45^{* *}$ & .06 & \\
Introjected Motivation & -.15 & -1.33 & .02 & \\
Autic Mastery Dominance & -.12 & -1.06 & .01 & \\
\multicolumn{5}{c}{ High-Frequency Exercisers $(\mathrm{n}=51)$} \\
Neuroticism & .11 & 0.97 & .01 & \\
Extrinsic Motivation & -.27 & $-2.13^{*}$ & .06 & $.36^{* *}$ \\
Intrinsic Motivation & -.27 & $-2.01^{*}$ & .06 & \\
Telic Dominance & .23 & 1.65 & .04 & \\
Negativism Dominance & -.00 & -0.01 & .00 & \\
\hline
\end{tabular}

Note. $s r^{2}=$ squared semi-partial correlation coefficient

$* p<.05 * * p<.01 * * * p<.001$

traversion $(r=.43, p<.001)$, and negatively associated with agreeableness $(r=-.26, p<.01)$ and conscientiousness $(r=-.23, p<.05)$. Autic mastery dominance was negatively related to neuroticism $(r=-.24, p<.05)$ and introjected motivation for exercise $(r=-.32, p<.01)$.

\section{Discussion}

Findings of the present investigation indicated a number of significant differences between low-frequency and highfrequency exercisers. Students who reported exercising more often tended to be in their upper years of study, and were more paratelic dominant than low-frequency exercisers. No significant differences were observed for extrinsic motivation, but high-frequency exercisers tended to be higher in introjected, identified, and intrinsic regulation of exercise behavior, generally showing a more autonomous style of motivation.

Among low-frequency exercisers, the strongest predictors of low body esteem were having a higher BMI and being higher in neuroticism. Autic mastery dominance was found to be associated with higher body esteem in this group, but was overshadowed in the regression model by the influences of BMI and neuroticism. Extrinsic and introjected motivations were also negatively correlated with body esteem, among individuals in the low-frequency group, but were not significant predictors in the regression.

High-frequency exercisers who were high in neuroticism showed poorer body esteem, as did those who were higher in extrinsic motivation for exercise. Among high-frequency exercisers, telic dominance was negatively related to body esteem, while negativism dominance was positively correlated with body esteem, but these metamotivational variables did not emerge as significant predictors in the final regression 
model. Intrinsic motivation was also negatively correlated with body esteem in this group.

Individuals who exercise with goals such as losing weight and gaining muscle mass are generally conscious of their efforts and the progress toward achieving their goal. This is characteristic of a telic dominant metamotivational style, in which individuals are very goal oriented and achieving the goal is a higher priority than the activity itself. Interestingly, when comparing frequency of exercise, it was found that low-frequency exercisers scored higher in telic dominance than high-frequency exercisers. This suggests that high-frequency exercisers may be more paratelic dominant. Perhaps the reason for this is that individuals who genuinely enjoy exercising do it more often because it brings them pleasure, and it is not simply a means to an end. Consistent with this line of reasoning is the finding that high-frequency exercisers also scored significantly higher on autonomous regulation (i.e., identified motivation and intrinsic motivation), in comparison to low-frequency exercisers, although the highfrequency group also scored higher on introjected motivation, which is a controlled regulation. Over all, then, the high frequency exercisers appear to have been engaging in more frequent physical activity because of an orientation to exercise that was less contingent on external consequences or pressures, and more concerned with autonomous satisfaction of internal needs.

Interestingly, there were no significant differences between low- and high-frequency exercisers on body esteem in the present investigation. This could be related to the fact that the two groups did not differ significantly in terms of BMI. BMI was a strong predictor of negative body esteem in the low-frequency exercise group, but was not significantly related to body esteem in the high-frequency exercise group. A possible reason for this finding is that the high-exercise group likely contained some very athletic individuals who exercised considerably more than twice per week, and whose activities included strength training exercises to build muscle mass. BMI is thought to be a poor measure of body composition in athletes, in that it can lead to overestimating body fat due to increased muscle mass (Burkhauser \& Cawley, 2008). Thus, it is unsurprising that BMI was a more influential predictor of body esteem in the low-frequency exercise group, which is less likely to contain highly muscular athletes.

Extrinsic motivation was found to be a negative predictor of body esteem in the high-frequency exercise group. Individuals who exercise three or more times per week and are satisfied with their body image are likely to be motivated by factors that are not extrinsic. Perhaps those who are satisfied with their body image are more likely to exercise regularly because they are not using exercise as a tool to achieve a specific goal. For these individuals exercise may be rewarding and therefore leisure time is highly anticipated. Extrinsically motivated individuals are interested in the results of their ef- forts and may become discouraged if they are not achieving their results, or doing so as quickly as they had anticipated. Those who exercise for intrinsic reasons will likely find it immediately rewarding because they enjoy engaging in the behavior, and this might lead to a more regular and persistent pattern of exercise.

Neuroticism was predictive of body image dissatisfaction in both exercise groups. In the low-frequency exercise group, neuroticism was positively associated with extrinsic motivation and introjected motivation. This suggests that individuals high in neuroticism experienced more controlled regulation of exercise in this group, likely engaging in exercise because of anxiety and guilt associated with not exercising, rather than for positive and pleasurable reasons. In general, neuroticism is associated with a tendency toward negative affect in self-report measures (Watson \& Pennebaker, 1989) and this might have resulted in individuals who were higher in neuroticism reporting poorer body esteem across both groups.

The present study also revealed some interesting associations between metatmotivational constructs from reversal theory and dimensions of behavioral regulation of exercise based on self-determination theory. Paratelic dominance was found to be associated with both identified and intrinsic motivation for exercise, indicating that those who are paratelic dominant tend to have more autonomous regulation of exercise behavior. Autic mastery dominance was associated with introjected motivation for exercise, which represents a more controlled motivational style. Considering the connections between metamotivational styles and exercise motivation can extend our ability to tailor exercise interventions to more effectively meet the needs of individual exercisers, as will be discussed below.

\section{Implications and Future Research Directions}

Understanding motivations for exercise is imperative in helping people adopt an active lifestyle. Initiating an exercise program is only the beginning; ensuring adherence to such a lifestyle must also be considered. Extrinsic motivations dominate in the initiation of a program but it is intrinsic motives that are important for maintaining it (Ingledew, Markland, \& Medley, 1998; Wilson, Mack \& Gratton, 2008). When designing a physical activity program at any level, there should be consideration as to whether its focus is on exercise behaviors or sport participation. Personal investment and satisfaction with exercise have been found to be strong in predicting adherence. Furthermore, the desire to perform exercise has been shown to predict greater frequency of performing the behaviors (Wilson, Rodgers, Carpenter, Hall, Hardy, $\&$ Fraser, 2004). An awareness of the reasons for an individual's initiation and adherence to exercise is fundamental when promoting healthy active living in a large population. Instead of focusing on a rigid exercise regimen as the only 
method, people should be presented with a variety of options. Since individuals have diverse personalities, the same style of exercise will not appeal to everyone.

Intrinsic motivation appears to be a stronger predictor of exercise adherence than other types of motivation (Wilson et al., 2004). This is not to say that individuals who exercise with specific goals do not adhere to exercise; being able to track progress may maintain motivation. However, setting goals and not achieving them can lead to a sense of failure and discouragement. To protect against such negative consequences it is crucial for individuals to find alternative styles of exercise that they enjoy doing. In an effort to promote positive health behaviors there needs to be an increased awareness of personality factors and motivations for exercise. People are interested in exercise for different reasons; some do it for the health benefits, others to change their physical appearance and others do it because it is fun. It is important for health promoters to be cognizant of the various forms of exercise that may be of interest to different individuals. Some prefer attending an exercise facility, while others prefer organized sports. Individuals and their personality characteristics will determine what style of exercise they prefer, but previous studies have found a link between intrinsic motivation and sport participation (Kilpatrick et al., 2005). These findings suggest that including sports activities in health promotion programs may be valuable to increasing individuals' participation in exercise activities.

In order to maximize the effectiveness of exercise programs, it is a key initiative to discover what form of exercise has intrinsic value to the individual. There can be immense variation in what form of physical activity might have intrinsic value for a particular person, including participation in sports, attending a fitness facility, and engaging in home fitness. Findings in this study demonstrated that low-frequency exercisers were likely to have telic dominant metamotivational styles. It may be practical for exercise coordinators to create programs that are better tailored to the specific motivational needs of their telic dominant clients, by applying the goal-oriented aspects of a telic motivational style to exercise and health promotion. For example, exercise programs can include an initial session where a health assessment is conducted and the individual is also tested on their maximum ability on certain exercises. The health professional might then discuss the individual's personal goals as well as implement a series of goals that the professional deems appropriate. Smaller incremental goals should be used to build up to the ultimate goal. There should be an ideal timeline for completing each goal. Including progress evaluations by the coordinator, with regards to the program, will help to ensure that individuals are continuing to advance. This also provides an opportunity for the program coordinators to ensure the maintenance of proper techniques. Telic dominant individuals are highly focused on setting and achieving goals.
A program such as this would allow individuals to track their personal progress and maintain a continuous effort to achieve goals. The impact that such a program would have on adherence is uncertain. Future research must focus on metamotivational and personality factors in relation to exercise adherence. Nonetheless, creating a range of fitness programs that are adaptable to different personality types and motivational styles is fundamental in the effort to increase exercise participation.

\section{References}

Apter, M.J. (2005). Personality dynamics: Key concepts in reversal theory. Loughborough, UK: Apter International Ltd.

Apter, M. J. (2007). Reversal theory: The dynamics of motivation, emotion and personality (2nd ed.). Oxford, England: Oneworld Publications.

Apter, M. J., \& Desselles, M. (2001). Reversal theory measures. In M. J. Apter (Ed.), Motivational styles in everyday life: A guide to reversal theory (pp. 55-76). Washington, DC: American Psychological Association.

Apter, M. J., Mallows, R., \& Williams, S. (1998). The development of the Motivational Style Profile. Personality and Individual Differences, 24(1), 7-18. doi: 10.1016/S01918869(97)00148-7

Awad, A.G., \& Voruganti, L.N.P. (2004). Body weight, image \& self-esteem evaluation questionnaire: Development and validation of a new scale. Schizophrenia Research, 70(1), 63-67. doi: 10.1016/j.schres.2003.12.004

Barnes, P. (2010). Physical activity among adults: United States, 2000 and 2005. NCHS Health E-Stat. Retrieved from: http://www.cdc.gov/nchs/data/hestat/physicalactivity/physicalactivity.htm

Blaydon, M. J., Lindner, K. J., \& Kerr, J. H. (2002). Metamotivational characteristics of eating-disordered and exercise-dependent triathletes: an application of reversal theory. Psychology of Sport and Exercise, 3(3), 223-236. doi: 10.1016/S1469-0292(01)00021-8

Burkhauser, R. V., \& Cawley, J. (2008). Beyond BMI: The value of more accurate measures of fatness and obesity in social science research. Journal of Health Economics, 27(2), 519-529. doi: 10.1016/j.jhealeco.2007.05.005

Deci, E. L., \& Ryan, R. M. (1985). The general causality orientations scale: Self- determination in personality. Journal of Research in Personality, 19, 109-134.

Deci, E. L., \& Ryan, R. M. (2000). The "what" and "why" of goal pursuits: Human needs and the self-determination of behavior. Psychological Inquiry, 11, 227 -268.

Gammage, K. L., Hall, C. R., Martin Ginis, K. A. (2004). Self-presentation in exercise contexts: Differences between high and low frequency exercisers. Journal of Applied Social Psychology, 34(8), 1638-1651. 
Ingeldew, D.K., Markland, D., \& Medley, A.R. (1998). Exercise motives and stages of change. Journal of Health Psychology, 3(4), 477-489. doi: 10.1177/135910539800300403

John, O. P., Donahue, E. M., \& Kentle, R. L. (1991). The Big Five Inventory - Versions $4 a$ and 54. Berkeley, CA: University of California, Berkeley.

Kilpatrick, M., Hebert, E., \& Bartholomew, J. (2005). College students' motivation for physical activity: Differentiating men's and women's motives for sport participation and exercise. Journal of American College Health, 54(2), 87-94. doi: 10.3200/JACH.54.2.87-94

Lafreniere, K. D., \& Cramer, K. M. (2006). Examining reversal theory measures in relation to NEO personality dimensions and consideration of future consequences. Personality and Individual Differences, 40(7), 1387-1397. doi: 10.1016/j.paid.2005.11.019

Lindner, K.J., \& Kerr, J.H. (2002). Metamotivational orientations in sport participants and non-participants. Journal of Sport and Exercise, 1, 7-25. doi: 10.1016/S14690292(00)00003-0

Mullan, E., Markland, D., \& Ingeldew, D.K. (1997). A graded conceptualisation of self determination in the regulation of exercise behavior: Development of a measure using confirmatory factor analytic procedures. Personality and Individual Differences, 23(5), 745-752. doi: 10.1016/S0191-8869(97)00107-4

Olivardia, R., Pope Jr., H. G., Borowiecki III, J. J., \& Cohane, G. H. (2004). Biceps and body image: The relationship between muscularity and self-esteem, depression, and eating disorder symptoms. Psychology of Men and Masculinity, 5(2), 112-120. doi: 10.1037/1524-9220.5.2.112

Rammstedt, B., \& John, O. P. (2007). Measuring personality in one minute or less: A 10-item short version of the Big Five Inventory in English and German. Journal of Research in Personality, 41(1), 203-212. doi:10.1016/j.jrp.2006.02.001

Rodgers, W. M., \& Gauvin, L. (1998). Heterogeneity of incentives for physical activity and self-efficacy in high active and moderately active women exercisers. Journal of Applied Social Psychology, 28(11), 1016-1029.

Rodin, J., Silberstein, L. R., \& Striegel-Moore, R. H. (1984). Women and weight: A normative discontent. In T. B. Son- deregger (Ed.), Nebraska symposium on motivation: Psychology and gender (pp. 267-307), Lincoln, NE: University of Nebraska Press.

Ryan, R. M., \& Deci, E. L. (2000). Self-determination theory and the facilitation of intrinsic motivation, social development, and well-being. American Psychologist, 55(1), 6878. doi: 10.1037/0003-066X.55.1.68

Shields, M., Carroll, M. D., \& Ogden, C. L. (2011). Adult obesity prevalence in Canada and the United States. National Center for Health Statistics Data Brief, 56. Retrieved from: http://www.cdc.gov/nchs/data/ databriefs/db56.pdf.

Sidman, C. L., Fiala, K. A., \& D’Abundo, M. L. (2011). Exercise motivation of college students in online, face-toface, and blended basic studies physical activity and wellness course delivery formats. Journal of American College Health, 59(7), 662-664.

Tantleff-Dunn, S., Barnes, R. D., \& Larose, J. G. (2011). It's not just a "woman thing": The current state of normative discontent. Eating Disorders, 19(5), 392-402. doi: 10.1080/10640266.2011.609088

U.S. Department of Health and Human Services. (2000). Healthy People 2010. Washington, D.C.: U.S. Government Printing Office.

Watson, D., \& Pennebaker, J. W. (1989). Health complaints, stress, and distress: Exploring the central role of negative affectivity. Psychological Review, 96(2), 234-254.

Wilson, P.M., Mack, D., Gratton, K. (2008). Understanding motivation for exercise: A self-determination theory perspective. Canadian Psychology, 49(3), 250-256. doi: 10.1037/a0012762

Wilson, P.M. \& Rodgers, W.M. (2004). The relationship between perceived autonomy and support, exercise regulations and behavioral intentions in women. Psychology of Sport and Exercise, 5, 229-242. doi: 10.1016/S14690292(03)00003-7

Wilson, P.M., Rodgers, W.M., Carpenter, P.J., Hall, C., Hardy, J., \& Fraser, S.N. (2004). The relationship between commitment and exercise behavior. Psychology of Sport and Exercise, 5(4), 405-421. doi: 10.1016/S14690292(03)00035-9 